\title{
Extending the Lining Life in Circulatory Vacuum Units at OAO EVRAZ NTMK
}

\author{
A. A. Metelkin ${ }^{a}$, O. Yu. Sheshukov ${ }^{b, c}$, I. V. Nekrasov ${ }^{b}$, E. A. Visloguzova ${ }^{a}$, \\ V. M. Kulik ${ }^{a}$, and V. V. Levchuk ${ }^{a}$ \\ ${ }^{a}$ OAO EVRAZ NTMK, Nizhnii Tagil, Russia \\ ${ }^{b}$ Institute of Metals, Ural Branch, Russian Academy of Sciences, Yekaterinburg, Russia \\ ${ }^{c}$ Nizhnii Tagil Technology Institute, Ural Federal University, Nizhnii Tagil, Russia
}

\begin{abstract}
Practical methods for extending the life of submersible tubes in vacuum chambers are considered. The structure of periclase-chromite components is studied. Refractories corresponding to optimal vacuumchamber operation in the converter shop at OAO EVRAZ NTMK are selected.
\end{abstract}

Keywords: refractory linings, operating conditions, vacuum unit, submersible tube, lining wear, mass transfer, bubbling

DOI: $10.3103 / \mathrm{S} 0967091213090106$

In efforts to reduce metal costs, it is important to extend the lining life in metallurgical systems [1]. In particular, the linings of vacuum units account for a considerable portion of total refractory costs.

Three groups of factors affect the lining life in circulatory vacuum units [2]:

(1) structural factors (the shape and size of the metal framework, the lining design, the format of the refractory pieces, and so on);

(2) the physicochemical properties of the refractories, which depend on the quality of the raw materials, the manufacturing technology, and so on;

(3) technological factors (the operating conditions of the metallurgical system, the slag composition and properties).

Specialists at OAO EVRAZ NTMK have been studying these factors, in order to improve the refractory components and optimize their operating conditions. The results assist in the development and introduction of new lining configurations with improved performance and longer life.

On that basis, measures have been taken to improve the operation of the vacuum units at OAO EVRAZ NTMK.

\section{STRUCTURAL FACTORS}

In the converter shop at OAO EVRAZ NTMK, the lining configuration illustrated in Fig. 1 is employed in the vacuum unit. A deficiency of this configuration is that the junction of the refractory ring and the refractory concrete at the end is rapidly worn, as is the region where the transporting gas is supplied (Fig. 2). During operation, the liquid steel penetrates into the damaged surface and erodes the metallic plate that supports the refractory rings at the end of the tube. That leads to settling of the lower ring of the tube and the formation of a gap between the rows of components. In subsequent operation, metal melt leaks into the gaps, producing local erosion around the circumference (Fig. 3). The vacuum chamber requires premature repair $[2,3]$. This problem at the junction of the refractory concrete and the refractory rings may be eliminated by adopting the design in Fig. 4. In that case, there is no horizontal junction between the concrete and the refractory ring, and the lower ring is rigidly fixed. In the course of operation, the modified structure does not permit perceptible settling of the refractory rings. The mean life in experimental vacuum chambers was 106.0 melts (as against 102.0 melts for mass-produced components).

\section{PROPERTIES OF THE REFRACTORIES}

Specialists at OAO EVRAZ NTMK pay great attention to the refractory components obtained from suppliers and, in particular, their susceptibility to wear [4]. Research shows that the unit wear of refractories in the discharge tube does not depend on the overall properties but is largely determined by the characteristics of the intake refractories. The operating conditions are most intense at the intakes: additional cooling of the refractory surface in the period between melts by neutral gas and considerable turbulence of the metal, which tends to erode the brick.

It is evident from the table that the components differ considerably in properties and working life. For more detailed information, samples are subjected to petrographic analysis after operation. As a result, we 


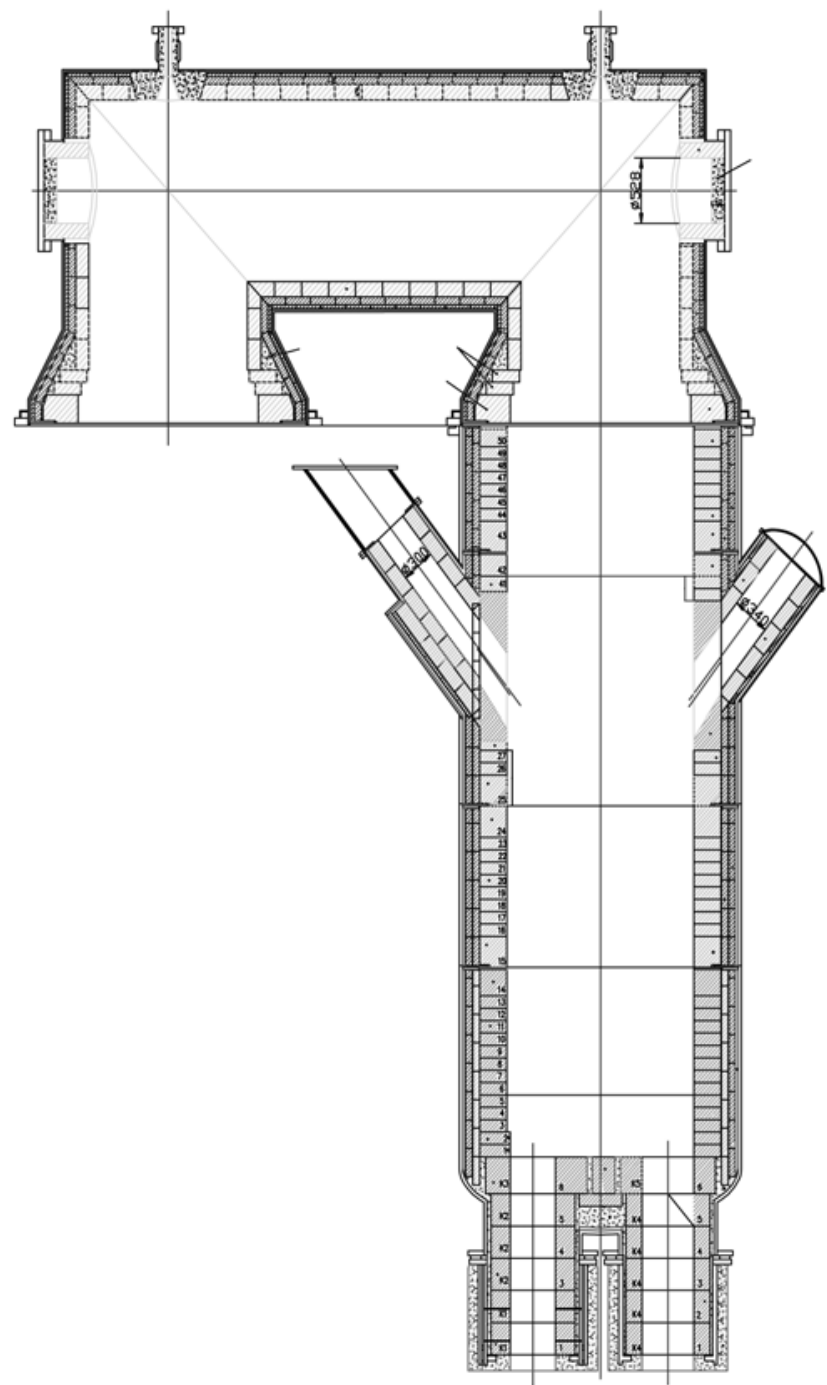

Fig. 1. Existing configuration of the refractory lining in the RH1 vacuum unit.

obtain data on the life and unit wear of three types of components:

$\begin{array}{lccc} & 1 & 2 & 3 \\ \text { Intake tube, mm/melt } & 1.08 & 1.79 & 3.12 \\ \text { Discharge tube, mm/melt } & 0.7 & 0.75 & 0.75 \\ \text { Mean life, melts } & 102.3 & 84.6 & 54\end{array}$

Comparison of the structure of the refractory components with their life and unit wear shows that the life is greatest for components based on fused periclasechromite with large crystals, uniform distribution of the chromospinelide, and additional reinforcement thanks to the addition of a small fraction of fused periclase-chromite (component 1). The life is shorter for highly fired components where the periclase and chromite have a direct bond with the smaller periclase-chromite crystals (component 2), and even shorter for components with insufficient contact

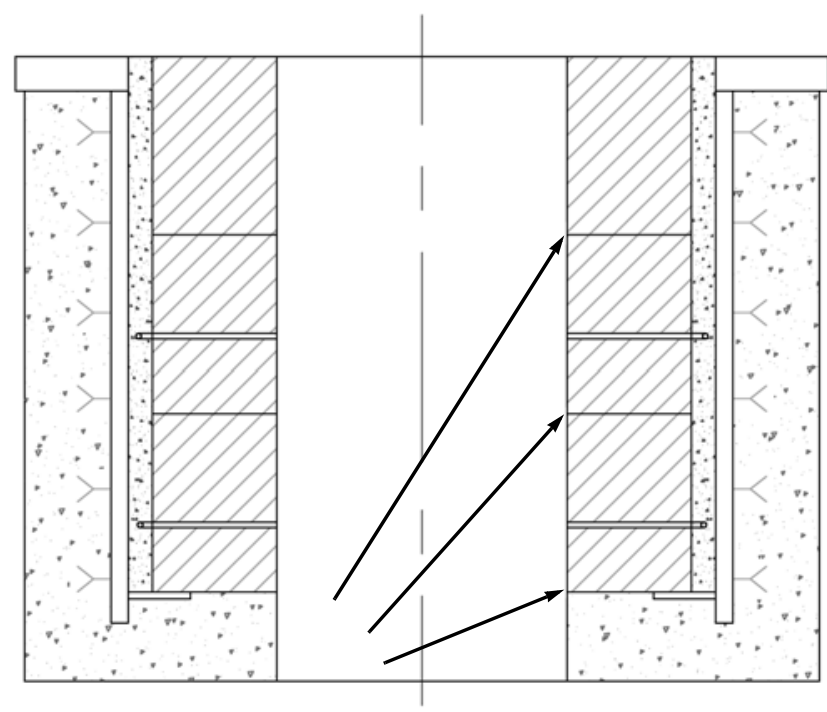

Fig. 2. Points of intense lining disintegration.

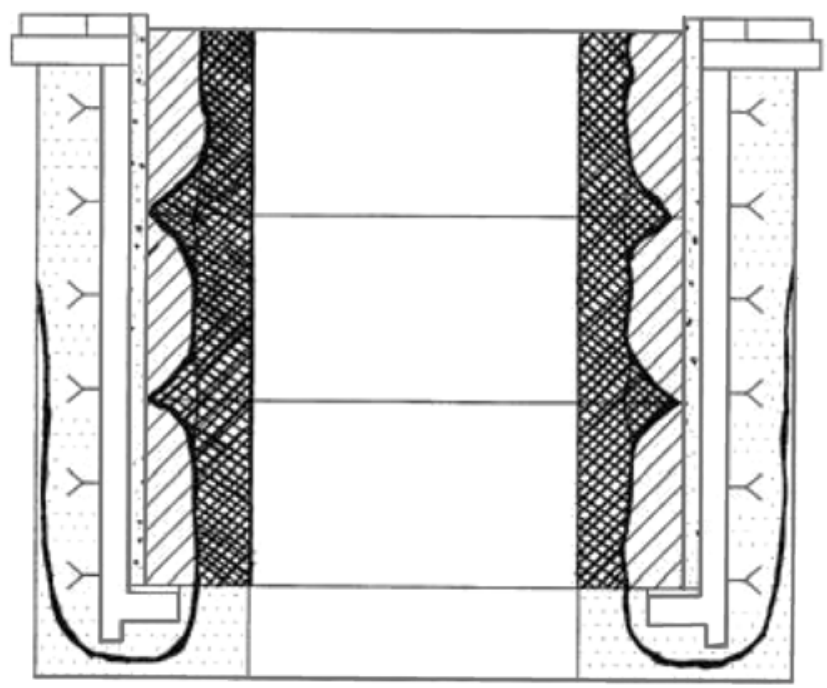

Fig. 3. Lining wear.

between the chromite and periclase grains and with inhomogeneous structure (component 3).

Research by specialists at OAO EVRAZ NTMK permits the identification of the optimal characteristics for components used in the working lining of vacuum chambers so as to ensure stable operation.

\section{TECHNOLOGICAL FACTORS}

The lining life in a vacuum chamber for degassing of the metal is more than 100 melts, with a total vacuum-treatment time of $22.5 \mathrm{~h}$. For a circulatory vacuum unit that processes steel for use in vehicles, the requirements on the residual hydrogen content are 

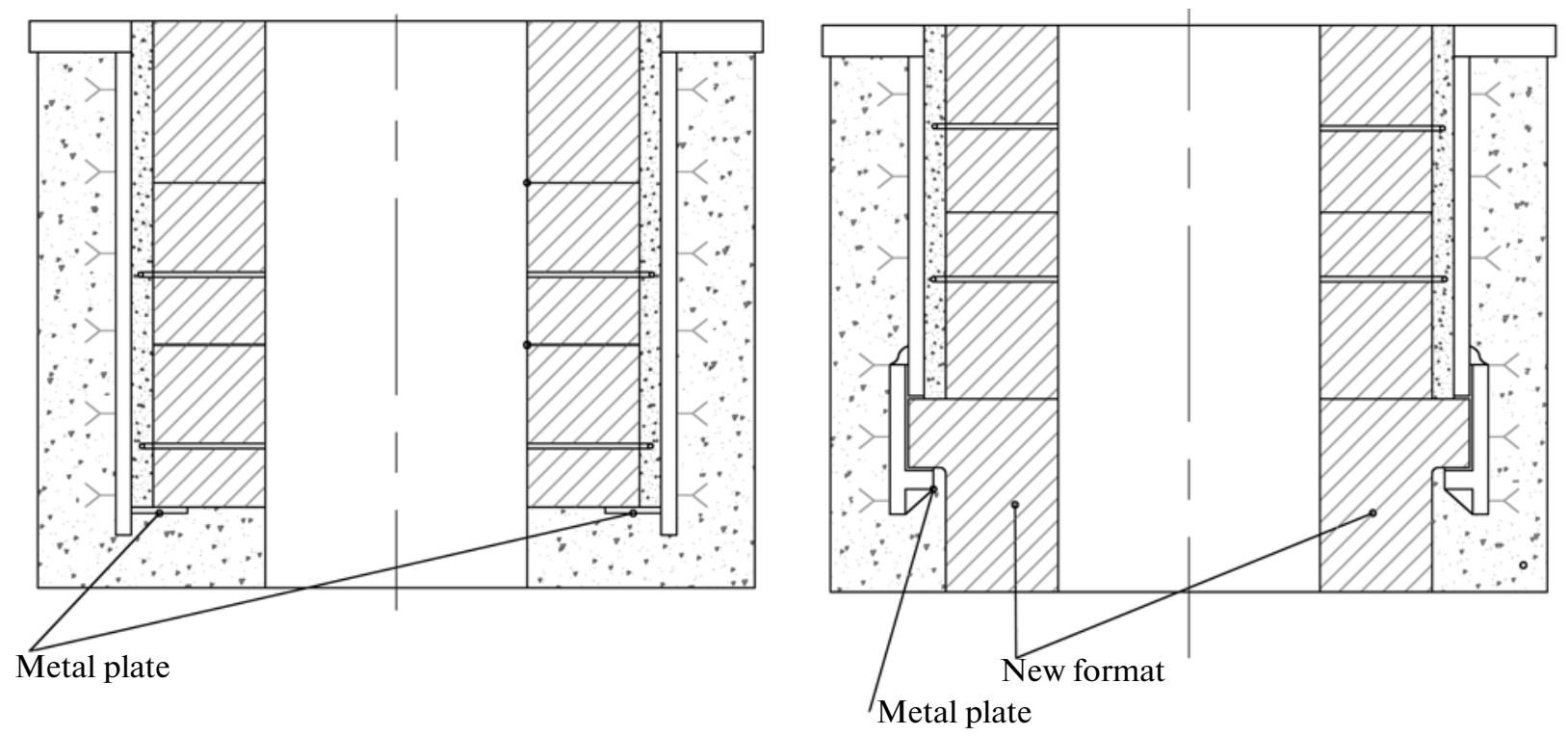

Fig. 4. New lining configuration.

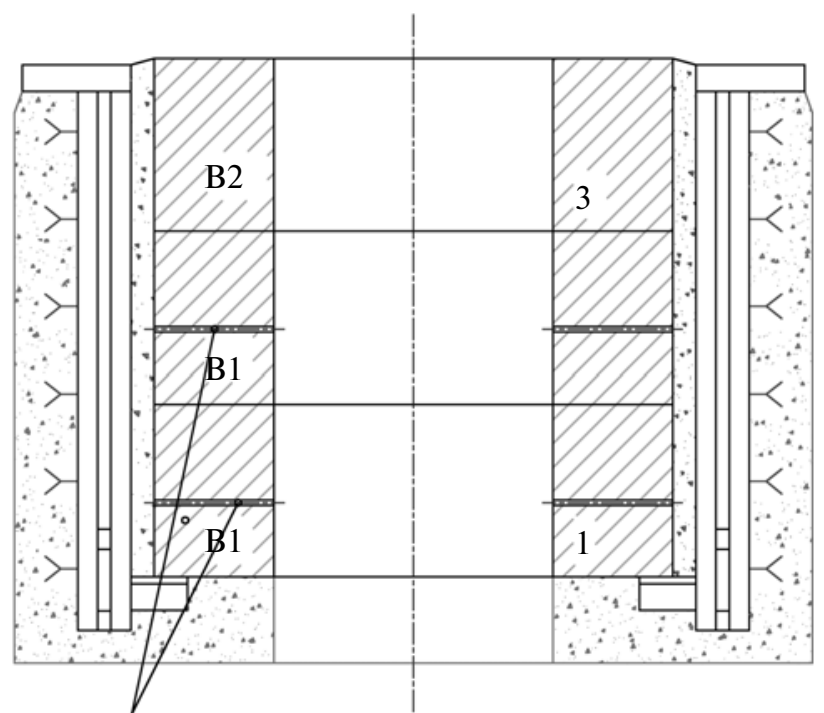

(a)

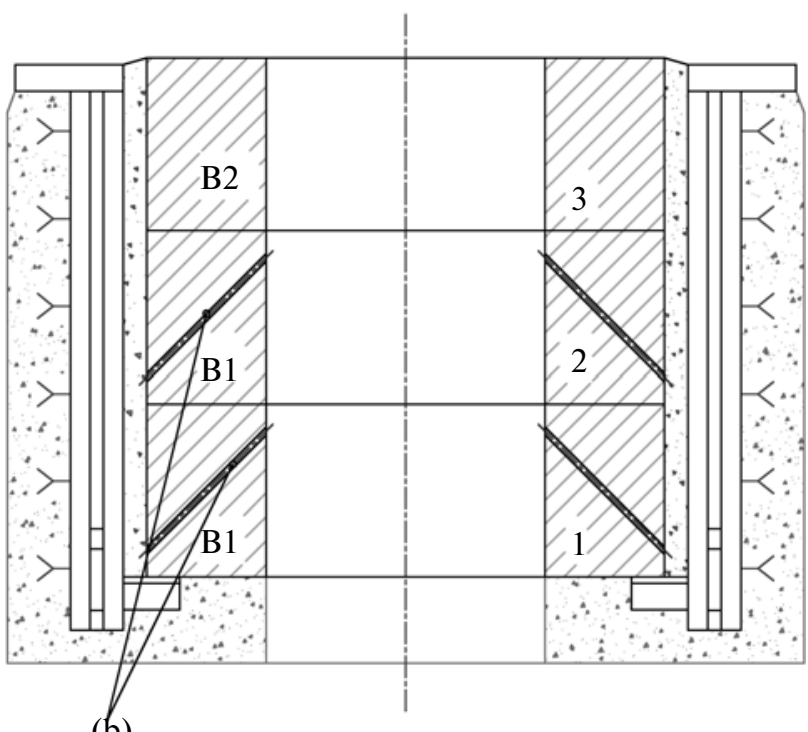

(b)

Fig. 5. Existing and experimental lining configurations: (a) with horizontal nozzles; (b) with inclined nozzles.

more rigorous, and so more prolonged treatment is required for each melt.

According to the theory of vacuum treatment, the degree of degassing may be increased by increasing the circulation rate, the mass-transfer coefficient, and the degassing surface. The degassing surface is limited by the vacuum-chamber design. Therefore, in existing equipment, it cannot be increased. The mass-transfer coefficient may be increased by increasing the supply of the transport gas (argon). However, with increase in gas flow rate, there will be more bubbling of the metal in the intake tube. That shortens the refractory life. Therefore, this method is of dubious utility. To increase the degree of degassing and so extend the life
Characteristics of three types of components

\begin{tabular}{|c|c|c|c|}
\hline & 1 & 2 & 3 \\
\hline \multicolumn{4}{|l|}{ Content, wt \%: } \\
\hline $\mathrm{MgO}$ & 66.19 & 57.77 & 73.1 \\
\hline $\mathrm{Cr}_{2} \mathrm{O}_{3}$ & 21.53 & 20.85 & 14.2 \\
\hline $\mathrm{Fe}_{2} \mathrm{O}_{3}$ & 6.74 & 13.03 & - \\
\hline $\mathrm{Al}_{2} \mathrm{O}_{3}$ & 2.98 & 7.40 & - \\
\hline $\mathrm{CaO}$ & 0.81 & 0.57 & 0.67 \\
\hline $\mathrm{SiO}_{2}$ & 0.88 & 0.38 & 1.05 \\
\hline Apparent density, $\mathrm{g} / \mathrm{cm}^{3}$ & 3.34 & 3.226 & - \\
\hline Open porosity, $\%$ & 11.4 & 16.2 & 14.0 \\
\hline Compressive strength, $\mathrm{N} / \mathrm{mm}^{2}$ & 108.8 & 45.2 & 44.4 \\
\hline
\end{tabular}




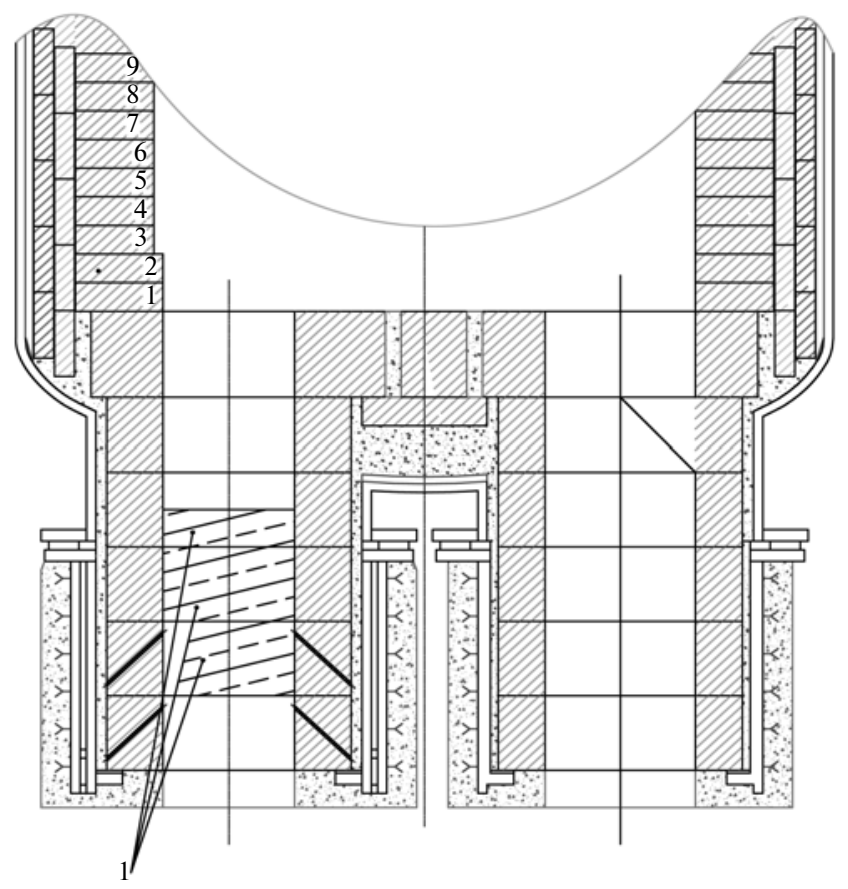

Fig. 6. Bubbling zone with inclined nozzles.

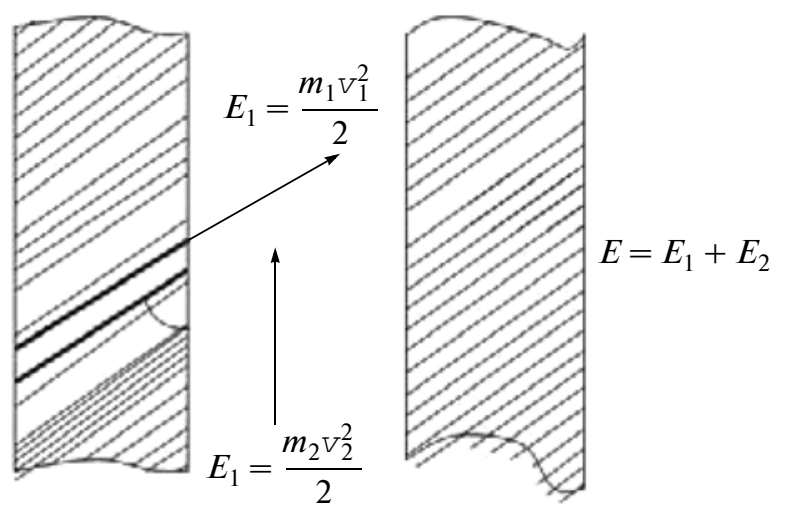

Fig. 7. Calculating the rate of metal circulation.

of the most worn point of the lining at the vacuum chamber's intake tube, we may adjust gas input by replacing the horizontal nozzles with inclined nozzles, as shown in Fig. 5.
As a result, we would expect longer lining life, since the bubbling zone will be shifted to higher refractory rings (Fig. 6). That will reduce the aggressive action on the lower rings, which are subject to the most intense wear. Increasing the distance between the nozzles and the refractory rings (by a factor of 1.4 for $45^{\circ}$ inclination) reduces the kinetic action of the gas on the lining. With change in the nozzle inclination, some of the gas's kinetic energy will be converted to kinetic energy of the metal, thereby increasing its flow rate. Consequently, the circulation rate of the gas is increased, and so the time required for vacuum treatment of a single melt will be reduced, with corresponding increase in the lining life (Fig. 7). In the prototype vacuum chambers with the modified design, the mean life is extended by $10 \%$.

Summing up, the lining life in vacuum chambers used in the converter shop at OAO EVRAZ NTMK is constantly being increased by improving the refractory components, optimizing their operating conditions, and introducing new lining configurations.

\section{REFERENCES}

1. Filatov, S.V., Visloguzova, E.A., Fomichev, M.S., et al., Extending the lining life in metallurgical equipment: reducing unit costs for refractories at OAO EVRAZ NTMK, in Trudy VI mezhdunarodnoi nauchno-prakticheskoi konferentsii s elementami nauchnoi shkoly dlya molodezhi, posvyashchennoi 80-letiyu MMK. Energosberegayushchie tekhnologii v promyshlennosti. Pechnye agregaty. Ekologiya (Proceedings of the Sixth International Conference and Seminar Celebrating the Eightieth Anniversary of OAO MMK: Energy-Conserving Industrial Technology, Furnaces, and Ecology), Moscow, 2012.

2. Sheshchukov, O.Yu., Vinogradov, S.V., Visloguzova, E.A., et al., Improving the operating time and reliability of vacuum-chamber linings, Stal', 2012, no. 1, pp. 20-21.

3. Metelkin, A.A., Koryukov, D.V., and Sergeev, V.N., Repair technologies and extension of the life of refractory vacuum-chamber linings, Novye Ogneup., 2006, no. 3, pp. 10-11.

4. Visloguzova, E.A., Metelkin, A.A., Zorina, L.V., et al., Influence of technological factors and the quality of periclase-chromite refractories on their wear resistance in vacuum-chamber linings, Novye Ogneup., 2006, no. 9 , pp. 35-38.

Translated by Bernard Gilbert 